\title{
Couture y su Obra Procesal (*)
}

\author{
(25 AÑNOS DE LABOR)
}

\author{
Por SANTIAGO SENTIS MEIENDO, \\ Profesor titular de Derecho Procesal y Director del Instituto \\ de Derecho Procesal de la Universidad Nacional del Litoral.
}

Hablar de Couture y de su obra procesal es más, pero también menos, que exponer su pensamiento procesal. Cuando, roco después de su fallecimiento. se cumplían 25 años de la fecha en que Couture inició su docencia en la Universidad de Montevideo, el Prof. Adolfo Gelsi Bidart dictó una admirable "clase sintética" que constituyó acto de homenaje a la memoria de Couture, exponiendo el pensamiento de éste en derecho procesal. El presente trabajo no puede ser como aquella lección, una síntesis sino todo lo contrario, un anólisis o al menos una exposición de la labor realizada por Couture a lo largo de sus 25 años de cótedra $y$ de producción escrita.

Examinar, además de la obra escrita, toda su labor científica y toda su actuación profesional no escrita, significaría un desarrollo imposible de contener en los límites de una exposición de la naturaleza de la presente.

Couture fue ante todo profesor; llegó a la cátedra en edad a la que muchos son todavía estudiantes; la ocupó con la altura y el dominio que caracterizó toda su actuación; nos quedan sus "Lecciones" que fueron origen de sus. "Fundamentos del derecho procesal civil", y nos quedan, publicados, sus "Cursos" monográficos.

Pero el Claustro de la Facultad lo elevó al Decanato y lo reeligió para ese cargo. Al trente de la Casa de Estudios puso de manifiesto sus dotes de organizador no solo en la marcha general de la institución sino tombién en aspectos particulares, como las publicaciones de la Facultad Y en particular la Revista.

(*) Este àrtículo, publicado en "La Ley", de Buenos Aires, ha sido gentilmente enviado por su autor al Decano de nuestra Facultad, Dr. Domingo García Rada, autorizando su publicación en nuestra Revista. Al hacerlo rendimos homenaje de respeto a la memoria del gran procesalista uruquayo, recientemente fallecido. 
La "Revista de Derecho, Jurisprudencia y Administración" lo nombró su Director; y fue estando Couture al frente de ella, cuando apareció el "Repertorio General" que recoge la labor de medio siglo; Couture pronunció con ocasión del homenaje que se rindió a la Revista, una de sus grandes oraciones y en ella expresó el recorrido del pensamiento jurídico del país en los tres órdenes que interesan principalmente a la revista: la doctrina, la legislación y la jurisprudencia.

Como profesor, como estudioso y científico del derecho procesal, Couture asistió a congresos y conferencias; a las que se celebraban en la Argentina como uno de la gran familia de esta tierra: asi en el Congreso de Ciencias Procesales de Córdoba (no asistió al que años más tarde se celebró en Salta como tampoco al recientemente celebrado en España). Y en Europa hubo de asistir al Segundo Congreso de Derecho Procesal organizado por las "Assoziacione Italiana fra gli studiosi del processo civile" que se celebró en Viena y fue designado miembro del Comité directivo de la Asociación Internacional que allí quedó constituida.

Hasta 1942 la abra escrita de Couture no es muy voluminosa; aparentemente, no es trascendental; $\mathrm{y}, \sin$ embargo, la jerarquía intelectual $\mathrm{y}$ espiritu del autor es ya la misma que se reflejará en su obra posterior. Pero este año de 1942, que es una línea divisoria en la obra escrita de Couture, que se destaca con la publicación de los "Fundamentos", queda esfumada cuando contemplamos en su conjunto la obra y la actuación, porque vemos que si lo más importante de aquella apareció a partir de ese año, existió siempre en la vida científica de Couture; ese año no parte dos etapas, de preparación la una y de realización la otra; la realización no pasa de ser un fenómeno puramente objetivo y material; pero en lo subjetivo y espiritual no determina una solución de continuidad. En el derecho procesal ria platense, ese año es el de mayor auge (para emplear la expresión en nuestros estudios un auge $\mathrm{y}$ un declive), pero en la vida de Couture es sólo, $\mathrm{Y}$ a lo sumo, el principio de una exteriorización de lo que ya venía existiendo. Se me permitirá, por eso, que señale la fecha por su importancia para quienes la labor únicamente tienen ocasión de apreciarla y valorarla en su producción escrita; pero que prescinda de ella al contemplar las distintas facetas de esa labor.

Negar el año 1942 el carácter de línea divisoria en la obra de Couture no quiere decir dejor de reconocerlo, desde un punto de vista objetivo $y$ externo, como el momento de mayor esplendor de nuestros estudios procesales.

Siempre que me he referido a esa época del derecho procesal en esta tierra; he considerado que estábamos ante un fenómeno rioplatense y no exclusivamente argentino. ¿Es que ha existido una verdadera vinculación entre argentinos y uruguayos en orden a los estudios procesales? ¿Es que se há trabajado coordinadamente? El fenómenọ fue mucho más simple, o quizá más complejo, que el de la normal vinculación o coordinación. Fué que tuvimos a Couture. Pero no como un órgano de enlace entre estudiosos de una $y$ otra orilla del Plata, sino como exponente de 
esos estudiosos uruguayos permanentemente incorporado y presente en la labor de este lado. Couture no es aquí un uruguayo sino uno más de la casa; a Couture no se le invita a dar una conferencia o a tomar parte en un Congreso como a un extranjero (si es lícito utilizar esta expresión entre gentes que hablan la misma lengua $y$ tienen tradiciones comunes) o co mo a un forastero; el concepto de frontera $y$ el de pasaporte se esfuman cuando aquí se trata del profesor de derecho procesal de Montevideo. Couture en las reuniones de juristas argentinos, es uno más, está en su casa; pero no como expresión formuiaria sino como realidad indiscutida; ese fenómeno, al menos en orden al derecho procesal, no tiene un precedente; es de desear que no quede sin continuación. Couture publica aquí la mayor parte de sus libros, los cuales circulan por todo el Continente ca mo libros de edición argentina; pero circulan en la Argentina también como libros orgentinos.

Queríamos encontramos de verdad ante un fenómeno intelectual rioplatense: pero quizá no estemos más que ante un fenómeno argentino con la participación destacadísima, de -proporciones muy amplias, de este Maestro que vive en la otra orilla. Couture está aquí én su casa; en verdad, "La Comarca y el Mundo" parece un símbolo; y cuando él sale de su comarca, en cualquier sitio del mundo, sea una populosa ciudad norteamericana, en una pequeña aldea holandesa, en París o en una histórica ciudad italiona, Couture se encuentra en un mundo propio.

Pero volvamos al derecho procesal de esta tierra y a la época de su mayor auge: a esos años 1941-1942 en que la producción de nuestros autores causa asombro a propios y extraños. Alsina publica el primer volumen de su "Tratado"; Lascano, "Jurisdicción y Competencia"; Podetti, "Teoría y Técnica del proceso civil", y Couture sus "Fundamentos del derecho procesal civil", (1) de desarrollos nada semejantes, de extensión dispar, de concepción distinta, respondiendo a mentalidades más homogéneas, hay sin embargo un denominador común en esas cuatro obras: responder a una preparación muy anterior; ser la expresión de un movimiento (2) que, iniciado unos años antes, encuentra en esos momentos su adecuada manifestación escrita. Porque no hay que creer que un tratado de la densidard del de Alsina sea un producto de la improvisación; es, por el contrario, el resultado de largos años de ejercicio de la docencia, de

(1).-Acerca de estas 4 obras véanse mis trabajos: "Ia ciencia procesal argentina", en "Revista de D. Derecho Procesal, año 1\%, 2 \% parte, pág. 22 y sigts.; "Del procedimiento al proce. salismo de la República Argentina", en "Revista peruana de ciencias jurídicas", año II. núm. 1, pág. 1 y sigts., $Y$ en "Annales del Colegio de Abogados de Sta. Fe" año 1, núm. I págs. 17 y sigts.; "Una década de Derecho procesal argentino", en "Soritti giuridici in orone della Cedom, nel cinquentenario della sua fundazione", vol. II. Padoba, 1952.

(2).- Así he venido denominando desde hace años, a la manifestación de log estudios procesales en esta tierra, y me complace ver compartida la denominación por el profesar Gelsi Bidart en su lección dedicada a presentar "El pensamiento de Eduardo Couture en derecho procesal". 
práctica de la profesión y de silencioso trabajo de gabinete; el libro de Lascano encuentra un magnífico antecedente en el "Proyecto de Código" redactado bajo su dirección siete años antes; a la gran monografía de Podetti se adelantó también en varios años su "Comentario al Código de Procedimiento Civil de Mendoza", y habían de sucederle los volúmenes de los varios tratados que forman su "Derecho procesal civil, comercial y laboral" que han ido apareciendo hasta después de su fallecimiento.

Couture contaba con doce años de producción científica que, comenzando en el "Divorcio por voluntad de la mujer". llegaba a "Trayectoria y destino del derecho procesal civil hispanoamericano" (de ellos me ocupo en parágrafo aparte).

Pero tampoco podemos suponer que estas cuatro cumbres estón aisladas en medio de una llanura; nadie discutirá la jerarquía máxima a estas cuatro obras que no han sido superadas en nuestra literatura procesal y que aparecieron cuando nada similar se había producido en otros países de lengua castellana, (3) pero no surgieron por generación espontánea. Si estos libros son la expresión de un movimiento científico que corresponde a la escuela procesal iniciada en Alemania y proseguida en Italia (mós difundida ésta que aquella entre nosotros) no se hace difícil encontrar antecedentes entre nuestics autores en cuanto al conocimiento de la escuela italiona y en particular de su fundador. Jofré, nuestro gran procedimentalista más que procesalista, es quien trae a los estudios de lengua casteliana la doctrina de Chiovenda, (4) pero la trae con tal éxito que, cuando pocos años después de su muerte, se realiza en Córdova el Primer Congreso de Cienciøs Procesales,( 5) el lenguaje que en él se habla es genuinamente, respondiendo a la denominación del certamen, el lenguaje procesal y no el procedimental; allí está presente la moderna ciencia del proceso que Jofré nos descubriera.

Y allí, junto a los maestros argentinos, como uno más de ellos, estó también Couture. Aquella reunión es el anuncio mós claro de lo que bien poco después se manifestará con la publicación de los cuatro libros a los que me he referido.

(3).-No puede dejar de recordarse que en aquella época, no se habían producido la "Exposición del derecho porcesal civil de España" de Prielo Castro, ni el "Derecho procesal civil español", de Manuel de la Plaza, ni el "Tratado de las pruebas civiles", de Rafael de Pina; que estábamos a mucha distancia en el tiempo de los "Comentarios", de Guasp, a Ia Ley de Enjuiciamiento civil española; y de las "Instituciones de derecho procesal civil", de José Castillo Larrañaga y Rafael de Pina... entre otros.

(4).-Sobre la influencia de Chiovenda en la doctrina de Jofré y la divulgación por éste de las obras de aquél, véase el trábajo de Alsina. "Influencia de la dartrina de Chiovenda sobre las estudios procesales en la República Argentina", en Revista de Derecho Procesal, año V. (1947), 19 parte ps. 317 y sigts.

(5).-Véase el volumen conteniendo "Antecedentes y actas del Primer Congreso Nacional de Ciencias Procesales", Imprenta de la Universidad de Córdova, 1942, Y el "Comentario de crónica procesal" de la "Revista de D. Procesal" año I, (1943) 2q parte, ps, 96 y sigts. 
Era necesario dejar constancia de que esa época magnífica en nuestra producción procesal, lo mismo para los autores argentinos que para Couture, lo fue de exposición y no de formación científica; si ésta no se hubiera ido acumulando a lo largo de los años anteriores, no se hubiera podido improvisar en un año ni se hubiera podido poner de manifiesto en aquella magnífica reunión de Córdova.

Un libro no jurídico: "La Comarca y el Mundo". ¿Es, en verdad, no jurídico este libro de Couture? ¿Es que, de los libros de Couture, sǒlo son jurídicos los que consultamos en los menesteres diarios de la profesión o de la investigación?. Nos vienen a la memoria dos frases: "El médico que sóio sabe medicina, ni medicina sabe", dijo un ilustre maestro del siglo pasado: " nos entusiasma Couture que ha hecho del Derecho procesal un canto $Y$ una danza", ha dicho un joven profesor $Y$ poeta venezolano de nuestros días. Sí; hay canto y danza en sus estudios de derecho; $y$ hay derecho en su itinerario por el mundo arrancando de su comarca.

No ha de ser pura casualidad el que cuando Couture contempla Roma desde el Pincio esté en compañía de Carmelutti; y que cuando queda en la Plaza de la Saloría, solo, pero bien acompañado, es Calamandrei quien lo ha llevado hasta allí, "después de poner Florencia a sus pies", para dejarlo meditando sobre la grandeza de Miguel Ângel, "el más grande de todos en las tres profesiones que emprendió"; y que cuando se decide a saborear el chianti "porque la historia y su responsabilidad lo mandaban", estaba en compañía del Rector Magnífico de la Universidad de Siena, otro jurista. $Y$ jurídico, Y, aún más, judicial es ver Washington no sólo como un jardín sino como la Corte Suprema de los Estados Unidos; es jurídico percibir en las Naciones Unidas el principio de una "larga $y$ enternecedora aventura humana"; ver en el palacio de cemento $y$ cristal, "la casa donde aspira a residir el gobierno de la especie humana"; $y$ es jurídico enfrentarse en Francia con Versailles y Fontainebleau; para recordar la admonición de Thiers de que "no debe entregarse la patria $\alpha$ un hombre, sea quien sea ese hombre $y$ fueren cuales fueren las circunstancias"; y detenerse en París en el Palais de Justice, ante una puerta por la que pasó María Antonieta o ante el sillón que fue de Fouquier Thinville, $y$ en el Hotel Majestic ante la carta que el abogado N. escribió al "batonnier" de su Orden antes de morir. Es jurídico, cunque el brillo de la frase amengüe la profundidad del concepto, ver en Suiza al turista como un objeto y no como un sujeto, y ver su organización financiera como una estación en la cual se juntan todas las vías férreas que transportan el dinero del mundo......... función en la que un día puede sustituíria el Uruguay. $Y$ jurídico es contemplar a los holandeses en su profesión de banqueros y en la de traficantes de piedras preciosas (además de tener esto último la virtud de conducirnos a un pasaje de Calamandrei en su "Elogio de los Jueces"), pero siempre como un ejemplo de honesta pobreza; $Y$ hasta la bicicleta holandesa adquiere silueta jurídica cuando la utilizan los novios para ir a casarse, con galera de felpa y ramo de azahar y cuando en ella van a divorciarse si las esperanzas no han sido colmadas. Es jurídico y 
es social percibir la clase media como" Ia comunidad en el goce de los bienes materiales, de la cultura, del arte, de la interrelación humana; comunided en el goce de la libertad política". Es bien jurídico el concepto de miedo, lo mismo si se representa en las torres múltiples de San Giminiano, la Cittá turrita, que si se percibe en la noche de Paramaribo, como factor determinante de la guerra. $\mathrm{Y}$ es, sobre todo, jurídico cuando se refiere a las graves ausencias que se observan en el libro: a "su silencio de España, de Inglaterra, de Alemania, de Grecia. Alguno de estos silencios está cargado de dolor y de pena". Es que ese dolor y esa pena no podían dejar de ser jurídicos, por lo que de antijurídico había en el origen de la ausencia $\mathrm{Y}$ del silencio. En fin; no debo seguir el itinerario de este libro admirable: "es probable que en ninguna página de este libro se hable en términos expresos de la universalidad de la cultura, de la primacía del espíritu, de la enseñanza de la historia, de la dura experiencia de la libertad, de las virtudes del trabajo, de la hermandad de todos los individuos de la especie humana, del poder de la ilusión del arte. Pero casi ciertamente no hay una página que no se halle impregnada de esas ideas".

Ninguna de las obras de Couture lleva el título de "Tratado"; ni de "Mcnual". Pero Couture fue un tratadista, porque lo es quien concibe una materic científica en su totalidad y en su conjunto; en la armonía de esa totalidad de conjunto; de igual manera que no es tratadista quien agota una materia amontonando un capítulo tras otro, aún en forma exhaustiva, sin un resquicio libre, pero sin haber percibido en momento alguno ia totalidad de la materia en su armonioso conjunto. Couture había concebido su "Tratado"; lo había planeado; había modificado el plan primitivo. Con la correspondencia que sobre ello cruzamos, podría acreditarlo detalladamente y acaso una parte del proyecto esté realizada. Pero también al no poner todo el esfuerzo al servicio de la realización de ese "Tratado", pudo haber algo de "premuerte"; es ahora cuando nos vamos dando cuenta de que la vida de Couture estaba demasiado influída por la idea de la muerte; y Couture no entregó a la imprenta más que trabajos acabados.

Pero esos trabajos acabados, perfilados, nunca parecieron estarlo lo suficiente para él; quien ha tenido como yo, el privilegio de intervenir en la edición de sus principales libros, sabe como se iban forjando hasta el úlitimo momento; cómo se realizaba ese delicado trabajo de lima que no acababa en el texto entregado a la imprenta sino que se prolongaba a través de la prueba de galeradas y de páginas hasta el momento mismo de la impresión.

Pudimos conocer sus "Lecciones de derecho procesal", aquellas lecciones que como las de Carnelutti, se publicaron en litografía; serían bastante para la fama de un profesor; sin embargo Couture, al publicar sus "Fundamentos" las consideró totalmente superadas, aunque en ellas había la levadura de un tratado.

Los "Fundamentos". Recuerdo aquel invierno de 1942 en que, página a página, y casi línea a línea fuí asistiendo a la aparición de la obra cumbre de Couture. Un volumen de 330 páginas, de modesta presentación 
tipográfica. Sólo quien no lo conozca, quien no se haya adentrado en sus páginas, podrá dudar de que en tan reducida extensión se encierre un tratado de derecho procesal civil. Para considerarlo como tal, sóio le faltaba, a mi modesto entender, un capítulo dedicado a estudiar la jurisdicción; así con toda sinceridad, lo manifesté en la Sesión del Instituto Bibliográfico del Colegio de Abogados de Buenos Aires en la que, actuando yo como relator, se examinó esta obra. (6) No podía haber en elro censura para Couture; no se criticaba una omisión sino un punto de vista; precisamente porque la jurisdicción no se estudiaba por Couture en los "Fundamentos", era objeto de estudio más amplio en otras producciones del autor; baste examinar el volumen primero de sus "Estudios". (7) Para Couture el tema de la jurisdicción correspondía al campo del derecho constitucional y no debía inciuirse como una de las partes de un libro orgánico de derecho procesal. El mismo criterio sostuvo al publicar la segunda edición de sus "Fundamentos" en 1951. (8) Si mis noticias responden a la realidad, creo que en la tercera edición, que el autor dejó preparada para la imprenta, ese criterio se modifica y la jurisdicción es objeto de amplio estudio.

En las dos ediciones publicadas, la obra consta de tres partes dedicadas a estudiar: la Constitución del proceso (la acción, la excepción, el proceso): el Desenvolvimiento del proceso (los actos procesales -en la primera edición el procedimiento-, la prueba, la sentencia), la Eficacia del proceso (recursos, cosa juzgada, ejecución). ¿No será suficiente esta enumeración de materias para poner de manifiesto que la obra contiene el desarrollo de un tratado, al menos en cuanto a la parte general, del derecho procesai?. No sería lícito repetir aquí el examen ya realizado en otras ocasiones de los distintos capítulos de la obra. Pero sí debo decir que no he encontrado otra exposición, no ya en nuestro idioma sino en la literatura procesal universal, que ofrezca una síntesis y una visión panorámica del proceso civil tan exacta como ésta y tan ajustada a los cónones cientín ficos del moderno derecho procesal; pero, al mismo tiempo, a su visión histórica. (9).

$\mathrm{Si}$ hubiese de contestar a la pregunta de si este libro reune las condiciones de un manual para la enseñanza universitaria, quizó lo hiciera negativamente; los "Fundamentos" tienen una densidad científica, una acumulación de conceptos y de noticias que exceden a lo que es lícito exigir, y hasta enseñar, al alumno de derecho procesal. Pero en cambio, es la obra más adaptada a las necesidades del abogado que, en la Universidad, estudió procedimientos judiciales en lugar de estudiar derecho

(6).-Véase nota 1.

(7).-Estudios de Derecho Procesal Civil", t. I., "La Constitución y el proceso civil",

Ediar S. A., editores, Bs. Aires 1948.

(8).--Véase mi recensión citada en nota 1.

(9).-Luego me referiré a la traducción realizada y a los proyectos de otras traducciones de esta obra cuya eficacia en cualquier ambiente científico, para adquirir el conocimiento exacto del derecro procesal, considero única. 
procesal. (10) Sabido es que pocas materias jurídicas (o ninguna) han sufrido una evolución científica mós intensa que la experimentada por nuestra disciplina; ni en el derecho civil, ni en penal, ni en constitucional, se ha producido un cambio tan terminante de doctrina y hasta de terminología, como se ha prnducido en derecho procesal (sería necesario acudir al derecho laboral para encontrar un fenómeno de tanto o más intensidad, ya que no paraleio). La escuela alemana desde Bülow (11) o desde Windscheid y Muther (12) hasta nuestros días; y la escuela italiana desde Chiovenda (13) significan una ruptura con el pasado, una solución de continuidad como no se ha producido en ningún otro itinerario científico. El libro de Couture recoge de manera plenc ese fenómeno; está científicamente al lado de acá del momento de ruptura, de la solución de continuidad; pero. sin desconocer en ninguno de sus detalles la evolución histórica hasta llegar a ese momento. Si la acción es para Chiovenda un derecho potestativo; si se manifiesta después la concepción que (con expresión poco feliz, como nos dice Couture) se denomina del derecho abstracto de obrar; si Couture, distinguiendo certeramente entre derecho, pretensión $\mathrm{y}$ acción, nos lleva a concebir la acción como forma típica del derecho de petición, no por ello puede olvidar que durante siglos el derecho procesal se alimentó de la clásica definición del Celso. Si el proceso es para la moderna doctrina una relación jurídica o una situación jurídica o una entidad jurídica compleja o hasta una Institución, tampoco quiere olvidar Couture que el proceso se explicó durante siglos como un contrato, primero, y como un cuasi contrato, más tarde.

(10).-No podemos alvidar que la enseñanza del derecho procesal en las Universidades. con la jerarquía y hasta con la denominación de tal, es cosa reciente. Hace paio más de un cuarto de siglo, los que cursábamos esta asignatura en las Universidades españolas lo hacíamos estudiándola bajo los títulos de Procedimientos judiciales (el primer curso) y de Dráctica forense (el segundo curso).

(11).-La obra de Bülow, "La Teoria de las excepciones procesales Y los presupuestos procesales", se considera por muchos autores como la iniciación del procesalismo moderno. Los primeros capítulos de esta obro pueden leerse en castellano en tradución del dostor Miguel Angel Rosas Lichtschein, en el "Boletín del Instituto de Derecho Procesal de lor Universidad Nacional del Litoral", nums. 4, 5 y 6.

(12).-La famosa "Polémica" entre estos dos autores, publicada en 1856 y 1857, con los títulos "Die actio romischen divilrechts vom stanopunkte des heutigen rechts", Düsseldorf, 1858; $y$ "Zur lehre van der romiscren actio, dem beutigen Klogreclit, der litizcontestation und der singularsurcession in obligationem", Erlangen, 1857, y que tuvo su continuación con la réplica del primero, titulada "Die actio Tbwehr gegen Dr. Th. Muthor", Düsseldorf, 1857, es obra muy difícil de encontrar en idioma criginal, pero hoy puede leerse en italicno. en una magnífica traducción de Emst Heinitz y cie Giovanni Pugliese, con admirable introducción de éste último que forma parte de la colección "I classici del dintto", dirigida por el profesor de Roma Francesco Calasso, publicada por la Editorial Sansoni, Fireize, 1954.

(13).-Toda la obra prozesal de Chiovenda se halla traducida al castellano; $y$ una buena parte de la obra de otros autores de la escuela italiana: Camelutti, Calamandrei. Liebman, Satta, Rocco. No sería correcto citar aquí todas las traducciones que existen de czos autores y que son conocidas de nuestros estudiosos. 
Los "Fundamentos", en esos nueve capítulos en que se desarroilan sus tres partes, constituyen una exposición metódica, hasta ahora insuperada, de la evolución y del panorama del derecho procesal. Recogien todo lo que esa evolución científica creó; lo metodizan con un sano espíritu ecléctico; y aportan sin perjuicios contra los materiales ajenos, elementos originales que completan aquellos. Entre esos elementos originales de Couture, habrá que conceder la primacía al concepto de acción como forma típica del derecho de petición. (14).

Estos son los "Fundamentos", que tanto han contribuído a dar jerarquía a los estudios procesales en lengua castellana; a que exista un "mo vimiento" (15) procesal rioplatense, ya que no una escuela procesal (16) que, al traducirse en Brasil al portugués, se han incorporado a la otra gran corriente letinoamericana (17) de derecho procesal, que, de realizarse el proyecto de su traducción al francés (18), podrían contribuir como ninguna otra obra de la nueva escuela, a la divulgación y asimilación de ésta en aquel país que ha permonecido al márgen de los estudios procesales, detenido en el más roncio procedimentalismo; y que en Italia (19) podrían alternar con entera dignidad al lado de las obras de los grandes maestros de la escuela procesal que fundara Chiovenda, de igual manera que su

(14).-Para estudiar, con toda su importancia, este tema, debe acudirse al trabajo de Couture "Ias garantías constitucionales del proceso civil", en el vol. I, de sus "Estudios", págs. 17 y sigts.: y a la $2^{\text {q }}$ edición, mientras no aparezca la tercera de los "Fundamentos del derecho procesal civil".

(15). - Véase nota 2.

(16).--Aunque no ha faltado quien ha querido dar la categoría de "escuela" a nuestro movimiento o corriente de estudios procesales, aún de vincularla a lá española, con injustificado olvido de que también en otros países de América han alcanzado considerable altura los estudios procesales.

(17). - No se puede desconocer la extraordinaria importancia do que en el Brasil han logrado los estudios procesales, así como la jerarquía de los maestros do ese país. Mención especial debe merecer el profesor italiano Enrico Tullio Liebman, quien vivió $y$ enseñó en el Brasil durante los años de su largo exilio. Intensa fue la vinculación de Couture con los estudiasos brasileños.

(18). - Para hacer conocer en Francia las corrientes procesales modernas, sería difíeil encontrar otra obra mós idónea que los "Fundamentos" de Couture. Tengo entendido que ios trabajos de traducción se iniciaron $Y$ que hubieron de luchar con obstáculos terminológicos de consideración. Ha de tenerse en cuenta que no existen traducciones de obres modernas italianas ni alemanas a ese idioma, lo que habró contribuído a que no se haya creado una terminología paralela que facilite la traducción, como la hemos logrado en nuestra lengua. Basta observar que el pequeño volumen conteniendo el cursillo que Couture "dictó en la Universidad de París, Y que en francés lleva el título de "Iintroduction á l'etude de la procédure civile". que para nosotros no resultaría exacto.

(19).-Couture consideraba una redundancia la traducción do su libro al italiano. Sin embargo no es del todo fácil encontrar en la bibliografía italiana, no obstante la amplitud de la misma y su inmensa altura científica, una obra que reúna las características de los "Fundomentos". 
autor pudo incorporarse, como un màestro, como un par entre pares, $\alpha$ los más gloriosos profesores italianos. (20).

El "Vocabulario de derecho procesal". Continuando lo que debió haber sido el itinerario hacia la meta de su "Tratado", Couture nos deja su "Vocabulario procesal" '(21). Un vocabulario o un diccionario, de cualquier materia científica, $y$ en particular jurídica, es difícil que se mantenga en un discreto término medio; o desciende a la vulgaridad, sin perjuicio de su posible utilidad práctica, o se eleva a la perfección que es belleza de orfebrería y ejemplo de exactitud, (22). Este es el caso de las voces que he tenido acasión de examinar en el "Vocabulario" de Couture; el concepto ofreciendo definiciones precisas de las distintas instituciones procesales; las etimologías, contribuyendo a la explicación y fijación de aquellos conceptos; las referencias legales, haciendo aumentar la utilidad práctica; y la traducción a los distintos idiomas, explicóndonos fenómenos científicos que han ofrecido dificultades y han sido obstáculos al desarrollo de la ciencia. (23).

Esto es lo que Couture nos ha dejado en el campo de las obras generales que estudian el proceso civil. Que su "Tratado", escrito como él hubiera sabido hacerlo, (24) habría podido contribuir a aumentar la jerarquía de la producción procesal en lengua castellana, (25) nadie puede discutirlo. Pero aún sin ese "Tratado", aún sin el primer volumen que Gelsi Bidart (26) nos anima a esperar, la obra de Couture queda completa, integral, sin lagunas, en su concepción y en su realización.

La obra general de Couture no tendría explicación sin la labor monográfica. Hay obras generales que tienen vida independiente, que nacen

(20).-Acerca de la actuación de Couture en Italia, vécse la reseña publicada en "Revista de Derecho Prozesal", año VII, (1949), 24 parte, ps. 194 Y sigts.

(21).-Con el título de "Notas para un vocabulario de derecho procesal" anticipó Couture sus ideas en el trabajo publicado en la "Revista de la Facultad de Derecho de Ia Méixco", número especial, t. III, abril - junio de 1953, núm. 10, ps. 115 y sigts.

(22).-Modelo de vocabularios juxídicos puede considerarse el que se redactí en Francia por profesores de Derecho, magistrados $y$ jurisconsultos bajo la dirección de Henri Capitant, $Y$ que apareció en 1936 con el título de "Vocabulaire juridijue", publicardo por "Las presses universitaires de France".

(23).- Puede ponerse como ejemplo el caso de la traducción de algunos vocablos alemanes que figuran en las famosas "Pandectas" de Windscheid y que en su traducción al italiano, nada menos que por Fadda y Bensa, originan ciertas perturbaciones al estu. dioso.

(24):- Couture, como él dice de Calamandrei, tenía tơmbién lo que Peguy llamaba "La pitié de lóuvrage bien faité". Para estos autores resultaba inconcebible la manera de procedimiento fascista,. inaceptable para el gran Vittorio Scialoja: hacer las cosas, pronto $y$ mal.

(25).-En la relativa pausa que en los últimos años se ha observado en nuestros estudios procesales, la aparición de un tratado de Couture hubiera tenido las proporciones de verdadero acontecimiento científico.

(26).- Así lo señala este profesor en la lección dedicada a la memoria do Couture a que me he referido. Moy de desear sería que esta esperanza se pudiera confirmar. 
cisladamente con prescindencia de toda otra producción, pudiendo ésta existir o no. Este no es el caso de la producción de Couture: las obras generales se apoyan en las particulares y se entrecruzan con ellas; los "Fundamentos" aprovechan la labor realizada en estudios monográficos; y la insatisfacción de algunos capítulos de la obra general, origina nuevas monografías que introducen variaciones esenciales en la nueva edición y que pueden dar lugar a transformaciones todavía más radicales en la que está por publicarse. Y el fenómeno lo vemos reproducido en el "Proyecto de Código de procedimiento civil" y en el "Vocabulario". Muchas deliniciones del "Vocabulario" han de encontrar su antecedente en estudios particulares; el mismo católogo de voces no ha podido ser extraño al que sirviera de base al "Repertorio General de "La Revista de Derecho, Jurisprudencia y Administración". Pero en la "Exposición de Motivos" del "Proyecto" vemos estudiado el litigio malicioso, utilizando lo que Couture había expuesto sobre "el Deber de decir la verdad en juicio" y sobre la "Regla Moral y Proceso Civil", así como también sobre el Precepto "Nemo tenetur edere contrase". Cuando presenta la estructura del proceso como "clósicamente liberal", lo hace basándose en lo que acerca de ello ha expuesto en "Trayectoria y destino del Derecho Procesal Civil Hispanoamericano"; cuando señala la orientación técnica de la reforma, recuerda io que acerca del tema dijo al prologar la obra de Cabal y Atienza; y así podríamos seguir la serie.

Couture empieza su obra monográfica con un estudio de verdadera importancia que, bien justificadamente, le abrió el camino a la cótedra universitaria: "El divorcio por voluntad de la mujer. Su régimen procesal". Si en su aspecto sustantivo pudo un parlamentario español calificar de "histerismo convertido en ley" a esta forma de divorcio, cuando se trató de introducirla en la República Española, sus particularidades de fondo debían repercutir fuertemente sobre las modalidades procesales, si es que no llegamos a decir que este divorcio se halla representado exclusivamente por régimen procesal. Couture sabe contemplar esas modalidades de un sistema procesal correspondiente a derechos de la mujer que dificilmente pueden merecer apróbación.

Un año después Couture ofrecía su 'Teoría de las Diligencias para mejor proveer". La trascendencia de esta obra es mucho mayor que la de la anterior en el itinerario científico de Couture (27). Porque no se limita a estudiar esta manifestación de facultades del juez en orden a la prueba, sino que la jurisdicción, la acción y la prueba estón tratadas como presupuestos teóricos de las diligencias para mejor proveer; pero tratadas contemplándolas en toda su importancia científica. En un examen a fondo del pensamiento procesal de Couture, quizá se encontrará que, de las ideas expuestas en este libro, casi todas ellas han sufrido una radical modificación; pero no puede dejar de decirse que nadie deberá llegar al estudio de esos conceptos en la futura edición de los "Fundamentos" sin arrancar

(27).-Muchas veces insisti cerca de Couture sobre la necesidad de reeditar este Iibro. 
de este libro, para continuar con otras de las admirables monografías de Couture, (en particular "Trayectoria y destino del derecho procesal civil hispano-americano") sin "entrar en la primera edición de los "Fundamentos". interrumpir de nuevo el itinerario con los "Estudios" sobre la "Tutela Constitucional de la Justicia", para seguir con la segunda edición de "Fundamentos". y nuevamente dirigirse a otras exposiciones de su doctrina, en especial a sus conferencias de París (de las que luego hablaré). Si pensamos que en la segunda parte de este libro se estudia la naturaleza jurídica $y$ formación histórica de las diligencias para mejor proveer, y que èn la tercerc, como régimen jurídico de esas diligencias, se estudion las prerrogativas del juez y el contralor de la parte, para terminar con el mecanismo procesal de esas diligencias, todo ello nos presenta el cuadro no ya de este libro, sino de la concepción global de Couture, dentro de la cual este libro es und zona de indispensable conocimiento.

Hay entre los trabajos de Couture que presentaron la categoría material del libro, otro que tuvo resonancia especial: "La Acción declarativa de prescripción" que, como algún otro de los suyos, fue mereciendo, a través de distintas redacciones, sucesivas ediciones (28). Este trabajo de Couture hace referencia a las ideas del Dr. Pablo de María y a su triunfo. (29) Y de ahi llega hasta la eficacia de la sentencia declarativa de prescripción que hoy nadie pone en duda; si hace variạs décadas se pudo calificar de "cerebro enfermo" a quien utilizaba tal acción, hoy habría que emplear el calificativo considerando anquilosado el cerebro de quien rechazara tal posibilidad.

Dos libros siguieron en 1936 y 1939 que fueron cursos universitarios: eir"Curso sobre el Código de organizcción de los tribunales" y el "Curso sobre lat ley ce chreviación de los juicios". Igual carácter presenta el que apareció en 1952 con el título de "Curso sobre las leyes de presupuesto del Poder Judicicl". En el "propósito" que figura al frente del segundo de estos cursos, Couture se pone a salvo de posibles críticas a la desproporción entre la importancia intrínseca de las nuevas normas y la amplitud de los desenvolvimientos del libro; y con cita de Henri Poincaré, nos dice: "Junto con las menudas y pueriles verdades del derecho, deben manejarse los principios, si es que el intérprete no quiere correr el tremendo riesgo de ser manejado por ellos".

La desproporción quizá exista, pero será en orden $\alpha$ lo que $\alpha$ un estudiante puede exigírsele que conozca de una ley especiali no, si esos cursos los contemplamos frente al deber de conocimiento del profesional.

(28).-Apareció primero, según nos dice Spota, en los "Cuadernos de la Asociación de estudiantes de abogacía", de Montevideo; luego en Buenos Aires, en la "Revista crítica do furisprudencia" 1934, ps. 27 y sigts.

(29).-Couture nos dice que "cuando por primera vez descrrolló los conceptos en qué se apoyaba su tesis, se calificó a ésta de irrisoria. Ia parte contra quien se invocó, dejá constancia de su protesta diciendo que "sólo la quimera puerli que ascitaba al enferma cerebro del outor, podía quebrantar su sosiogo liǵndolo a un graroso fuício". De esto hacé más de 30 años. Hoy la teris es absolutamente indiscutible en nuestro pár"." 
Complemento del "Curso sobre el código de organización de los tribunales" fue el cursillo dictado en el Centro de Estudiantes de Derecho en la primavera de 1938, y cuya segunda edición, de 1943, tengo a la vista; en él, se tratan problemas puramente procesales, porque los de organización fueron objeto de aquel otro curso.

Publicaciones independientes fueron también su relación acerca "De la organización judicial y del régimen procesal", a la Primera Convención de Abogados del Uruguay, celebrada en Montevideo en Setiembre de 1944; en cuatro apartados trata los siguientes temas: 1) Nombramiento y promoción de Magistrados; II) Del principio de especialización en la a cidministración de justicia; III). Defensa letrada obligatoria; IV) Reforma al proceso civil y penal; $y$ en 1947, en la "Revista del Notariado" (órgano del Colegio de Escribanos de Buenos Aires) publicó "El concepto de la Fe Pública", en el que, en seis capítulos' de Introducción. al estudio de derecho notarial, no sólo se exponen la idea, el concepto, el contenido y la función de la fe pública sino to que es más interesante para nosotros, la eficacia procesal $y$ la eficacia sustancial de la fe pública (30). Difícilmente se encontrará en la bibliografía notarial un estudio sobre la materia, desarrollado con el método y con la elegancia de éste.

No es posible, cuando de la producción monográfica de Couture se trata, agotar el tema, porque Couture era inagotable. Algunas de las monografías a que acabo de referirme aquí, algunas de las conferencias a que me referiré en otro parágrafo figuran en sus volúmenes de "Estudios", donde hay muchos más que no fueron objeto de publicación separada.

Pero la importancia de los tres volúmenes de "Estudios" (31) ya publicados $y$ del que muy en breve creo los continuará, está en el sistema que se siguió para su publicación. Otros autores (32) han reunido sus estudios en reproducción literal sin introducir en ellos ninguna modificación; cuando más los han agrupado con arreglo a un cierto orden. Los de Couture han formado volúmenes de materias independientes: "La Constitución y el proceso civil", el primero; las "Pruebas en materia civil", el segundo; "EI juez, las partes y el proceso", el tercero. Pero no es eso sólo. Son textos nuevos; $y$ quien ha intervenido en su transformación material en volúmenes, sabe lo profundo de esa transformación: fue material e intelectual; muchos de los trabajos fueron totalmente reelaborados. Por eso yo debo decir a los estudiosos que el pensamiento de Couture hay que buscarlo en esos volúmenes (creo que hoy agotados) y no en las primitivas publicaciones; y que hay que buscarlo en esos volúmenes........ mientras no haya sido modificado con posterioridad a su publicación; porque bien pudiera ocurrir que la ma-

(30).- - Hecuerdo que en mis tiempos de estudiante, la materia notarial en la carrera de derecho, como de escasa importancia, se enseñaba en la Universidad por el Profesòr de Procedimientos Judiciales y la Práctica forense, como apéndice a esta materia.

(31). - Véase mi nota bibllogrófica al primer volumen de 'Estudios" en "Revista del

Derecho Procesal", año VI (1948), 29 parte, ps. 151 Y sigts., Y la acta bibliogrática de Podetti al vol. II, en la misma revista, año val (1950), $2^{q}$ parte, ps. 12 Y sigts.

(32:- - Así Chiovenda que, en las sucesivas ediciones, los agrupó por materias; $I$

Carnelutti y Calomondrel, que siguieron un orden cronológico. 
teria objeto de algún estudio incluído en esos volúmenes hubiera sido reelaborada después en la nueva edición de "Fundamentos" o hubiera sido objeto de algún estudio particular. La obra de Couture es siempre interesante en sus detalles, pero exige que se la conozca en su conjunto; por lo demás, otros grandes maestros, Carnelutti por ejemplo, requieren esfuerzo similar.

Dentro de la necesidad, de la obligatoriedad de conocer toda la obra, no quiero dejar de destacar las más altas cimas de la producción mono gráfica. En el volumen primero, como alfa $\mathrm{y}$ omega, el primer trabajo "Las garantías constitucionales del proceso civil" significa, al menos para mi, la elaboración científica más densa y más original que realizó Couture; me atrevería a decir que su más trascendental aportación a la ciencia del proceso; $y$ el último "Trayectoria y destino del derecho procesal hispano-americano" representa una de las producciones literariamente más bellas que salieron de la pluma de Couture (aunque originariamente constituyera un cursillo de conferencias) y una contemplación dinámica originalísima de lo que el proceso civil ha sido, es y puede ser. En el segundo volumen "Las reglas de la sana crítica y la "Declaración judicial de la prescripción adquisitiva", dos trabajos que antes fueron libros, pueden reclamar los puestos preferentes sin que importe, para mi, la posibilidad de una discrepancia en cuanto a la manera de entender el concepto de sana crítica. El tercero, sin duda alguna "Interpretación de las leyes procesales" (sus conferencias en México), es el trabajo de mayor jerarquía del volumen; después la "Función del proceso en el "common law" y en la codificación" ofrece la importancia de representar un esfuerzo que para Couture tuvo la móxima trascendencia: el de armonizar o aunar lo que, en la evolución jurídica, han significado esas dos manifestaciones, aparentemente antagónicas, de la vida del derecho.

Han trascurrido once años desde que se publicó el "Proyecto de Código de procedimientos civiles". La solidaridad rioplatense era entonces, como hoy (y como siempre aunque las manifestaciones de ella hayan podido ser muy diversas), absolutamente perfecta; y al homenaje que los colegas uruguayos le rindieron, organizado por los antiguos compañeros de curso universitario, no podíamos dejar de estar presente amigos de esta orilla del río. En las palabras de Couture en aquel acto (33) fue bien poco lo que él quiso decir de su obra; pero no pudo por menos de señalar la necesidad de convertir en colectiva la obra que hasta entonces era individual. Y aqui, entre nosotros, el "Proyecto" fue objeto de encuesta (34) Y se le tomó en consideración en todos los trabajos de codificación que desde entonces se han llevado a cabo en el campo procesal.

Cuando, en el año 1940, Couture había prologado la obra de Cabal y Atienza (a la que hago referencia en otro lugar de esta exposición) no dejó de señalar los diversos criterios con que una labor codificadora puede

(33).-Véanse las reseñas publicadas en "Revista de Derecho Procesal", año III (1945) 24 parte, ps. 381 Y sigts.; $Y$ año IV (1946), $2^{q}$ parte, ps. 77 Y sigts., espelcialmente pág. 185. (34),-En la "Revista de Derecho Procesal", año V (1947), 1q parte, págs. 112 I slgts. 
emprenderse. Esos criterios aparecen todavía más terminantemente contemplados en su "Proyecto": "Ira redacción de un código no es obra académica sino una obra política. No tiene por finalidad consagrar principios de cátedra, sino solucionar los problemas que la realidad social, económica, cultural y ética presenta al legislador". No puede expresarse de manera más diáfana una gran verdad. Y porque se trataba de contemplar ante todo esa realidad, el autor no creyó que su mirada bastase para tal contemplación ni que su criterio hubiese de ser el único definidor de ella; por eso, las palabras finales de la Presentación del Proyecto a la Comisión fueron para pedir que se iniciase la encuesta a que se refieren las Bases o Programa de la reforma; y para decir su propósito personal de procurar contacto con los profesores y magistrados de todo el país a fin de comprender sus necesidades $\mathrm{y}$ tenerlas presente en la medida de lo posible. $\mathrm{Si}$, como se dice más adelante en la Exposición "el nuevo código debe ajustarse al sistema democrático consagrado en la Constitución", el procedimiento para formarlo no podía ser más democrótico y así lo entendía y quería ponerlo en práctica Couture. Ignoro lo que de esa labor de encuesta se llevaría a cabo en el Unuguay $\mathrm{y}$ sus posibles resultados; quizá, como tantos otros proyecios el de Couture haya de continuar siendo lo que el no quiso que fuera: obra académica y doctrinaria. Pero, cun en tal caso, no ha de considerarse obra inutil; aun en alcanzar la finalidad para la que él la forjó, la obra no dejará en lo sucesivo, como no ha dejado hasta ahora, de gravitar en el panorama de la codificación procesal; y tampoco será uno mós añadido a la extensa lista de proyectos. De igual manera, el de Lazcano en la Argentina no será un proyecto sino el Proyecto.

Vamos a ver como llevó a la práctica Couture esa obra política, no académica, que es la formación de un código. En primer lugar, sentando unos principios, que en el orden político, son los que antes se han señalado, de ajustarse al sistema democrático consagrado en la Constitución $y$. en el orden técnico, la sencillez, probidad y eficacia; la distinción entre organización y procedimiento; y en cuanto al costo de la justicia, que este sea razonable.

En cuanto a la justicia uruguaya actual, hay en el proyecto una afirmación categórica de Couture: "el país se considera satisfecho con sus jueces", $\mathrm{y}$, enseguida, "la primera convención nacional de abogados ha reconocido recientemente que el país ha considerado siempre resuelto el problema de la independencia del Poder Judicial". (¿puede desear más un país en lo que atañe a la administración de justicia?).

Es muy importante que un país esté satisfecho de sus jueces y que así se afirme por una convención de abogados y por quien, además de su personal autoridad científica, ha de ocupar los decanatos de la Facultad de Derecho $Y$ del Colegio de Abogados. Pero un país puede estar satisfecho de sus jueces Y. no de su justicia; estudiando el Proyecto Couture y en particular su exposición, se llega a la conclusión de que existen motivos para que el Uruguay desee una mejor justicia, porque la buena justicia no es producto que se origine única y exclusivamente en la independencia 
de los jueces (35). Hay un amplio parágrafo en ese capítulo de la Exposición, en el que se trata de la duración del proceso; y causa asombro y desaliento enterarse de que, entre los asuntos que se han tomado para realizar una estadística, son mayoría los que han exigido una tramitación de más de cuatro años en la primera instancia y de dos años para arriba en la segunda instancia libre; esto es seis años por lo menos para llegar a la sentencia de segunda instancia. Couture nos dice: "esta lentitud parece sèr endémica en nuestro país" y añade que "la naturalidad de nuestra justicia lenta nos envuelve y nos domina" pero sobre todo, nos dice que los magistrados" apenas la perciben por su falta de contacto con los interesados que los priva del espectáculo de su desesperación" (la bastardilla es mía); y nos dice también que "en el procedimiento, el tiempo es algo más que oro, es justicia" ¿no habrá algo de contradicción entre "espectáculo de la desesperación" y el tiempo que es "justicia" (en el caso de la lentitud quiere decir que es injusticia), por un lado, y la "satisfacción del país con sus jueces" por otro?. Couture no propuso, frente $\alpha$ ese mal endémico, una "justicia fulminante" sino una "duración razonable", con rapidez que, como en el caso de la magistratura austríaca", no es en desmedro de la Justicia". Se refirió después a la malicia, a la inmoralidad de la justicia; y por último, a su ineficacia, con alusión al "contempt of Court", institución desconocida entre nosotros. "Abreviar la justicia no es pues, solamente hacerla más rápida; es hacerla más oportuna, más limpia, y sobre todo, mas eficaz". Enseguida veremos cómo se llevaban a la práctica esos postulados de sencillez, probidad y eficacia.

En cuanto a la orientación política de la reforma, Couture la condensó en estas palabras; "La ley procesal es la ley reglamentaria de las garantías constitucionales inherentes a la justicia civil"; $\mathrm{y}$ "la acción es una forma típica del derecho constitucional de petición".

Cuando cumplamos ese deber que tenemos todos los estudiosos de derecho procesal aun los que nos contamós entre los más modestos, de examinar, desmenuzar, valorar y criticar la obra de uno de nuestros grandes, como ha sido Couture, quizó lleguemos a la conclusión de que la aportación más sólida y más personal que Couture nos ha dejado se contiene en el descrrollo de esos dos conceptos que acabo de trascribir. Sus trabajos más originales están en esa línea científica.

No he tenido ocasión de conocer el nuevo texto de sus "Fundamentos"; pero se me ha dicho que en él figura un amplio capítulo dedicado a la jurisdicción. No tengo la pretensión de que mi insistencia acerca de la necesidad de tal capítulo en una obra general de derecho procesal haya influído sobre el autor, ya que de haber ocurrido así, hubiera podido darle entrada en la $2^{\text {q }}$ edición; lo que creo, para el caso de que ese capítulo se redactora por Couture, es que llegó el momento en el que percibió

(35).-Debo insistir acerca de lo que en otras ocasiones he dicho sobre la justicia in. glesa: la independencia de la magistratura y la honorabilidad de los jueces son factores esencialísimos, pero no únicos para lograr una buena justicia. 
con absoluta claridad, la vinculación entre el plano procesal $Y$ el plano constitucional, en lo que se refiere a la acción, como poder jurídico del particular, y la jurisdicción como función del Estado; y habrá sido entonces cuando la jurisdicción, sin perder su carácter constitucional, habrá podido entrar en su estudio procesal, de igual manera que la acción, concepto esencial del proceso, forma támbién parte integrante del campo constitucional. Habrá así una perfecta armonía entre los preceptos constitucionales y su desarrollo procesal (36).

Ahora bien, el carácter democrático en una Constitución y de un código procesal que desarrolle sus preceptos, no puede ser obstáculo para que la dirección del proceso se confíe al juez: "Políticamente hablando, el juicio debe quedar en manos de la autoridad".

En cuanto a la orientación técnica, como desarrollo del programa político y en perfecta armonía con la visión amplia, con el carácter flexible, que ha de ser ecléctico en ocasiones. Couture nos dice: "No hay procesos orales puros ni escritos puros" (37); en cuanto a los hechos se quiere lograr una mayor inmediación no sólo en el procedimiento oral sino también en el escrito, ya que "la prueba es la parte más significativa del proceso y en la gran mayoría de los casos de ella depende la sentencia".

Couture se hace eco de los argumentos que se oponen a la inmediación: "que el juez necesita su tiempo para hacer sentencias y que le es materialmente imposible recibir la prueba. Se añade, no sin razón, que cuando los testigos declaran el juez nada sabe del asunto, del que recién ten. drá una idea clara cuando el juicio se halle pronto para dictar el fallo". Pero hay que tener muy presente el párrafo que figura a continuación $y$ que es aplicable no solamente al Uruguay: "Ambas observaciones son fundadas: pero como admitirlas conduce, simplemente, a seguir como hasta ahora, y lo actual es inaceptable, se hace indispensable superar en la mo

(36).-No hay que creer, sin embargo, que en la historia se produce siempre la coincidencia sobro el carácter político de un régimen $y$ el desarrollo legislativo del país. Couture lo dice con toda claridad ("Proyecto", edición fuera de comercio, p. 51): Por circuns. tancias de orden histórico, el código vigente está inspirado en el derecho de una mancar, quía hereditaria $y$ fue promulgado el siglo pasado por una dictadura militar". Es lamentable pero cuando las dictaduras se prolongan no queda otro remedio a sus sucesores que recoger la herencia legislativa, siquiera debe hacerse con el beneficio del inventario $\Psi$ realizando éste con el mayor cuidado. Lo que no debe pretender as dar como inexistentes varios años do vida nacional, con todo lo que a lo largo de ellos se legisló. Por lo demás támbién Couture señala (pág. 52) que en cuanto a la nocesidad de que el pueblo comi prenda la justicia han coincidido recientemente tres ideologias políticas bien distintas, coma se observa en las Relaciones o Exposiciones de motivos del Código brasileño de 1939. del italiano de 1940 del mexicano de 1940.

(37).-Couture reconoce la poca disposición de los profesionales a la oralidad: "Ioa abogados prestigiosos no tienen ningún interés en lanzarse por nuevos $Y$ destconocidos cat minos: los abogados jóvenes temen a la inferioridad que les crearía su inexperiencia en el duelo oratorio: las insólitas comodidades que el juicio escrito depara a los jueces, hace a Éstos, adversarios del sistema. 
dida de lo posible esas objeciones. El Proyecto trata de superarlas por distintos modos" (38).

Cuando del Derecho se trata, el problema de la mediación o de la inmediación lo resuelve imponiendo la defensa letrada obligatoria, porque este problema "no es solamente técnico sino que tiene también un sentido social que rebasa el ámbito del proceso".

Frente a la cuestión del impulso procesal, la solución es clara y terminante; se mantiene la iniciativa y la disponibilidad en manos de los litigantes; pero se reserva el impulso a los órganos de la jurisdicción. Así, "de acuerdo con la orientación publicística del derecho procesal moderno, punto sobre el cual ya no hay discusión, pues el consenso es unánime, el Juez debe participar del proceso desde el día mismo de su promoción"; y por ello, el Proyecto comienza por confiar al Juez, antes que a cualquier otro, el poder de dirección del proceso (art. 3\%).

Para conseguir la orientación práctica de la reforma, Couture proyecta la simplificación del procedimiento, reduciendo el número de escritos, haciendo más sencillos los juicios que no tienen oposición, reduciendo el formalismo en la documentación $y$, sobre todo, descongestionando las oficinas del inmenso expediente de la tramitación judicial del proceso sucesorio, cuando exista acuerdo entre los herederos (39). Cuida después, de asegurar la probidad en el debate judicial, tratando de eliminar al improbus litigator, para conseguir que reine en los límites de lo posible, la buena fe en el proceso civil. Y, por último, para lograr la mayor eficacia de la justicia, y ante la imposibilidad de llegar a la "penalización del proceso civil"., la plantea en cuanto al proceso de ejecución.

(38).-Se ha querido, entre nosotros, insistir en la Imposibilidad del juez de intervenir en la prueba $Y$ de conocer el asunto descle el primer momento para volver, en orden. a nuestro proceso civil, a dejar las cosas como estaban $Y$ derogar el precepto más pro fundamente innovador de nuestra legislación judicial: el art. 23 de la Ley 14,237. Se ha: dicho $y$ repetido que el Juez no dispone de tiempo para estudiar el asunto desde su inicio. con desconocimiento absoluto de que el estudio desde el primer momento, además de ser la única forma racional de conocer un asunto significa una verdadera economía de tiempo y sobre todo de esfuerzo: se olvida cuando se argumenta que los jueces necesitan su tiempo para hacer sentencias, que son precisamente los jueces que carecen de tiempo. para intervenir en la prueba los que también suelen carecer de él. para harer las sentencias, limitándose, cuando más, a dictar el fallo. dejando su fundamentación al personal auxiliar; y que los jueces vérdaderos cumplidores de su deber, y que hacen por sí mismos las sentencias, en su parte dispositiva $y$ en sus fundamentos, suelen encontrar tiempo para dirigir y presenciar la prueba, única forma de llevar con un perfecto conocimiento el momento definitivo del proceso.

(39).-Al verificar esa descongestión resuelve con verdadera gracia un problema práctíco de la intervención profesional en el proceso civil: el abogado se opone a la interven. ción del notario en los juicios sukesorios; pero los notarios alegan las repercusiones económicas de tal eliminación. Couture desplaza a los notarios de un gran número de actuaciones menores, en su parte no litigiosa, que continuarán siendo fuente de ingresos para sus titulares, dejando a la actividad del juez la homologación de lo tramitado ante el escribano; $Y$ distribuye entre abogado y escribemo los derechos de arancel. La solucién, además de original, parece equitativa. 
Nos explica, finalmente, el método seguido para la reforma: cómo se consiguió reducir su extensión material a menos de la mitad de la que tiene el código vigente; los esfuerzos que exigió el propósito de lograr claridad y sencillez, esfuerzos que hàn de tener su complemento en la tievia sión a fondo del texto, desde el punto de vista gramatical, por especialistá a fin de evitar cualquier expresión imperfecta. Se señala la ausencia de definiciones, que el codificador no debe formular; se hace una enunciación de los códigos y proyectos que se han tenido presentes; se indica la estructura del proyecto, $y$ se termina justificando la omisión en él de las fuentes sin concordancias, porque "la ley, se ha dicho, es más inteligente que el legislador".

Esto es lo que Couture expuso acerca de su Proyecto. Nada sé sobre la suerte corrida por esta obra suya: si se tomó en consideración por el Poder Legislativo o si, por el contrario, pasó a engrosar el número infinito de los proyectos de ley no discutidos por los parlamentos. Aún en este caso, la obra de Couture habrá sido de la mayor utilidad. Como otros proyectos, tales el de Chiovenda y el de Carnelutti en Italia, y entre nosotros el de Jofré, el de Lascano y el de Reimundín, se habrá incorporado a la literatura procesal ya que no a la legislación procesal; lo cual tiene sus ventajas aunque no deje de ofrecer sus peligros, porque el Proyecto que no pierde esta condición y que no se enfrenta con la realidad de la vida judicial, ofrece al teórico sus virtudes y excelencias, pero no somete a la piedra de toque de la práctica sus posibles errores y deficiencias.

Yo tengo el firme convencimiento de que el "Proyecto Couture" hubiera podido convertirse en código sin tropezar con obstáculos prácticos. Creo que los Principios Generales que forman sus nueve primeros artículos, hubieran podido ejercer una saludable influencia sobre el espíritu de los buenos jueces y que en el peor de los casos, nada perjudicial habrían significado para aquellos otros que no hubieran sabido adaptarse a su espíritu. Considero verdaderamente lamentable que no se haya hecho el ensayo del juicio sumario y del juicio oral en lo civil, con la posibilidad de la revisión del fallo en un juicio ordinario posterior (arts. 222 y 246). Creo que hubiera exigido un examen muy a fondo todo el Libro Quinto de la Parte primera dedicado a la jurisdicción voluntaria, sobre todo en lo que se refiere a la declaratoria de incapacidad; en cuanto al proceso sucesorio, estimo que su. regulación contiene grandes aciertos; pero, desconociendo en absoluto la vida judicial uruguaya, no puedo opinar acerca de los posibles resultados prácticos. En su Parte segunda el proceso de ejecución presenta un método que sólo pudo darle quien estaba en posesión de una ciencia y de una técnica perfectas; y no atribuyo excesiva importancia a la inclusión en ese libro del Tit. V dedicado a regular la ejecución de las sentencias extranjeras, que yo hubiera querido ver en otro lugar del código, como proceso de cognición y para regular la eficacia de esas sentencias -como dice la rúbrica del primero de los artículos- más que su ejecución; es un problema tan solo de ubicación, ya que lo regulado en esos artículos, es, con toda claridad, la homologación y no la ejecución.

De la parte tercera, disconformidades de detalle, como la que podríamos referir a la apelación de las providencias de trómite y a la posi- 
bilidad de modificarlas de oficio no deben ser objeto de examen especial; y tampoco sería procedente hacer hincapié en un examen general, sobre la admisibilidad de la jactancia; ello puede ser examinado en un estudio particularizado y no de conjunto.

E] "Proyecto Couture" está incorporado, como lo he dicho antes, a la literatura, ya que no a la legislación procesal. $\mathrm{Y}$ ese "Proyecto" con los "Fundamentos", con el "Vocabulario" Y si, por suerte para la ciencia procesal, Couture hubiera dejado escrito el primer volumen de su Tratado de que nos habla Gelsi Bidart, constituye la obra general de nuestro autor. Al lado de ella, la monográfica es un complemento $\mathrm{y}$ también una base sólida.

Aunque no signifique una labor codificadora, de formación de leyes, me parece que es aquí, a continuación de lo que acabo de decir, donde debo hacer referencia $\alpha$ dos libros de Couture:

"Legislación vigente en el Uruguay", en colaboración con Héctor Hugo Barbagelata, es un volumen sistemático, en 300 páginas más 16 de minuciosos índices alfabéticos, en que los autores responden a un programa elaborado por la Unión Panamericana y se refiere a la legislación vigente en el Uruguay hasta el 31 de diciembre de 1950. El peligro de esta clase de trabajos no solo puede estar en lo deficiente de los datos sino en la falta de visión, en la estrechez del panorama. Huelga decir que ambos peligros quedaban eliminados al encomendarse el trabajo a esto; profesores que representaban una garantía no solo en lo que se refiere a la labor personal sino a la visión de un mundo jurídico, amplia y clara.

"Código de Procedimiento Civil concordado y actualizado". "Entre tanto en nuestro país se prepara la opinión para una nueva legislación procesal, es menester seguir usando el código vigente, actualizando los viejos artículos con los posteriores modificativos". Couture había preparado un Proyecto de Código en el que "había tratado de conservar todo lo válido y fecundo de esa vasta experiencia legislativa y de innovar respecto de las instituciones que consideramos caducas y anacrónicas"; pero hasta tanto que ese proyecto pudiera, con más o menos modificaciones, convertirse en ley, había que seguir caminando: la justicia no puede detenerse y el derecho tiene que proporcionarle los mecanismos necesarios; quien supo preparar un nuevo código, bien podía actualizar el cuerpo legal al que su obra quería reemplazar.

¿Qué predominaba en Couture, el escritor o el orador?. ¿Era más perfecto hablando o escribiendo?. Sería difícil decirlo: haría falta, en primer témino, ponerse de acuerdo a lo que debe caracterizar al orador; porque no ha faltado quien negase a Castelar el título de orador, porque su gran memoria le permitía repetir discursos previamente escritos; pero la gran memoria, creo yo que será una ayuda y no un obstáculo para el que de verdad sea un gran orador. Couture fue un hombre de extraordinaria me moria y fue, también, un gran orador. ¿Hasta donde repetía o reproducía sus propias palabras, previamente escritas o preparadas?. ¿Hasta donde sus oraciones ercon producto de la improvisación. Su condición de orạdor le daba precisamente esa imposibilidad de distinguir entre lo improvisado 
- facultad indispensable del orador-y lo preparado -manifestación de solvencia también del orador-. Couture no ocupaba una tribuna sin una frevia preparación; ningún orador solvente procede de otra manera, salvo en casos de absoluto compromiso. De esa preparación forma parte siempre la cuidadosa confección de guiones; si el podía prescindir de tal ayuda en el momento de su actuación ante el público, no sería un defecto sino un mérito más; y si era capaz de sustituir, en el curso de la oración, una parte preparada por otra improvisada, sin que se percibiese la menor so. lución de continuidad, sería este uno de sus grandes méritos de orador. Couture no fue -afortunadomente- parlamentario; no fue político. Pero en la vida científica háy algo que exije agilidad mental como la que necesita un buen parlamentario y con un fondo de mayor solidez; son las sesiones de mesa redonda, ton frecuentes hoy. Couture dominó también ese estilo; luego me referiré a su actuación en México y en París.

Querría hacer aquí un itinerario geogrófico a la par que intelectual de Couture; querría situar sus oraciones en el marco respectivo, pero quizá no sea este el lugar adecuado, porque aquí se trata sobre todo de poner de manifiesto lo que Couture nos ha dejado como obra escrita, como labor utilizable para los que han de seguir estudiando derecho procesal; y en tal sentido aunque algunas de las conferencias las hayan escuchado, lo que interesa es su texto reproducido o reconstruído, aunque por razón de la especial manera en que esos textos se ofrecieron por primera vez, los hagamos objeto, de un grupo especial. Por lo demás estas conferencias que voy a citar, como textos posteriormente escritos, figuran varias de ellas en los volúmenes de sus "Estudios"; pero originariamente fueron comunicaciones con el público. No pretendo agotar la relación de las que Couture pronunció, sino referirme a algunas que, por el tema y por su desarrollo, han dejado honda huella.

Couture llevó su palabra a otros países donde expuso el derecho procesal: a Italia (40), al Perú (41), a Chile (42), a Cuba (43), a Estados Unidos (44). Contamos con reseña de su actuación en esos países, pero no con el texto de las respectivas conferencias en algunos de ellos. Me limito aqui a indicar lo que fue esa actuación en los casos en que he dispuesto del texto escrito.

Argentina. Su conferencia sobre "Oralidad y regla moral en el proceso civil" se pronunció en la Facultad de Derecho de Buenos Aires bajo los auspicios de la "Asociación pro Juicio Oral" el 25 de agosto de 1938. La

(40).-Véase "Revista duł Derecho Procesal", año VII (1949), 2q parte, pág. 194 Y sigts.

(41).-Véase "Revista de Derecho Procesal" año V (1947)., 2a Parte, pág. 65.

(42).-Véase "Revista de Derecho Procesal", año XI (1953), parte 2ă, pág. 41.

(43).-Véase "Revista de Derecho Procesal", año In (1945), parte 2a, págs. 106 y sigts.

(44).-Véase el "Informe" del decano de la Facultad de Derecho de Montevideo doo tor Couture, al Consejo de dicha Facultad, sobre su actuación en la Universidad de Tulane, en el que se indica que el curso dictado en aquella Universidad lo fue en inglés $Y$ llevó por título "A camporative Survay of Latín American civil procedure", que se desenvolvió en veinte lecciones, dictadas en los meses de tebrero y marzo de 1955, distribuídas en una in aroducción, Primera y Segunda Parte $\bar{y}$ una Conclusión. 
obra codificadora de Klein y la de Chiovenda exponiéndose en sus resultados, la primera, y en su tendencia, la segunda, del juez fantoche al juez investido de autoridad; la oralidad no como espectáculo sino como manera de solución de los conflictos:

"Las reglas de la sana crítica en la apreciación de la prueba testimonial" fueron objeto de una conferencia en la Facultad de Derecho do Buenos Aires, el 27 de julio de 1940. Esta conferencia es un punto de partida. A contar de ella, la expresión y el concepto de "sana crítica" cobraron nuevo valor en nuestro derecho procesal, al que esa expresión pertenece desde que una ley española del pasado siglo la utilizó por primera vez. Couture con Alcaló-Zamora son los autores que han vuelto a poner sobre el tapete este concepto procesal, tendiendo a sistematizarlo.

"La acción revocatoria de la cosa juzgada fraudulenta", conferencia pronunciada el 16 de noviembre de 1940 en el Centro de Estudios Jurídicos de La Plata que presidía el Dr. David Lascano. El fraude procesal preocupó siempre a Couture; lo trata en esta conferencia; se ocupó támbién de el en "Oralidad y regla moral"; lo relacionó con el deber de decir verdad; lo llevó más tarde $\alpha$ su Proyecto donde el litigio malicioso fue contemplado en toda su importoncia.

"Trayectoria y destino del derecho procesal civil hispanocmericano". A fines de 1940 dictó Couture un cursillo de tres conferencias en la Universidad de Córdova: el pasado, el presente y el futuro del derecho procesal civil. El interés de estas tres lecciones si es grande por los datos que en ellas se contienen, es maryor aun por la forma en que la trayectoria está vista y el destino está percibido o deseado. La belleza literaria intensifica el interés y el valor. El derecho procesal está tomado, como dijo al iniciar el cursillo, en dos dimensiones: una de tiempo y otra de profundidad. Pero es la tercera de las conferencias la que ha de tomarse en cuenta con especial cuidado: al fin y al cabo el derecho procesal romano o las fórmulas del Fuero Juzgo pertenecen a la historia y el problema es de datos y depercepción; la situación actual en Europa y en este continente también puede estimarse objetiva. Pero en el futuro de 1940 la incertidumbre ad. quiría su grado máximo; y la incógnita no se ha despejado todavía. Acaso debe relacionarse esta incógnita con el trabajo aparecido en 1951 "¿Crisis del derecho procesal?" (45). Porque la crisis en 1951 puede explicar la incertidumbre en 1940.

Uruguary. De la labor de conferenciante de Couture en su propia tierra, tomamos un ejemplo. "La Justicia Inglesa" (conferencias pronuncia. das en la Universidad de Montevideo bajo el patrocinio de la Asociacióm de Amigos de Inglaterra). Habló del juez inglés, del common law y del sentido político de la justicia inglesa. Es posible que yo no participe del optimismo que animaba a Couture sobre la justicia inglesa; quizá me resista a considerarla la mejor justicia del mundo; 0 de aceptar esta opinión, quizá la calificara de la menos mala, porque no puede considerar perfeccio-

(45).-Véase el trabjo publicado con este título en "Revista de Derecho Procesal", añd IX (1951), parte 19, págs. 195 y sigts. 
nes su "carócter rudimentario", su "lentitud" ni su "carestía". Pero Couture hablaba en 1943; $Y$ era bastante mérito en aquellos momentos "realizar el increible milagro, en medio del tragor de esta guerra en la que se juegan su destino, de haber continuado, imperturbablemente como lo relata una anécdota de estos días, literalmente entre bombardeos, la misión de defender las libertades inglesas y las de sus propios enemigos".

México. En febrero de 1947, Couture dictó un cursillo en la Escuela de Jurisprudencia (hoy Facultad de Derecho) de la Universidad Nacional Autónoma de México, sobre, "Interpretación e integración de las leyes procesales". A las tres conferencias siguió una sesión de mesa redonda, pero no sobre lo expuesto en las conferencias, sino sobre los principios generales que figuran al frente del Proyecto de Código redactado por Couture para el Uruguay. Puede asegurarse que la crítica más constructiva que sobre ese proyecto haya podido realizarse es la de aquella sesión que se prolongó por varias horas, y en la que los nueve artículos fueron examinados I desmenuzados. Cuando pueda hacerse el examen detallado de toda la labor de Couture, no podrá faltar el de esta sesión de mesa redonda, en la que a la attura del ponente correspondió la de los otros participantes (46),

Francia. En la primavera de 1949, dictó Couture un Cursillo en la Facultad de Derecho de la Universidad de París, seguido de una sesión de mesa redonda. Del pequeño volumen en que las conferencias y la sesión se recogieron, me he ocupado ya con alguna extensión, poniendo de manitiesto la trascendencia del suceso (47). Por primera vez -así pareció resultar de la sesión de mesa redonda- en la casa de estudios que fundara hace siete siglos el ilustre capellán del Rey San Luis, se escuchara una concepción moderna del proceso; la doctrina alemana y la italiana no les llegaba a los profesores franceses por boca de un profesor de aquellos países; ni siquiera de un español que, al-menos por razones de vecindad, hubiera podido hacerlo sin tan largo viaje; no: el lenguaje, nuevo para los colegas franceses, era el de un americano que les llevaba lo que ellos tenían a las puertas de casa; pero habían sabido vivir largos años sin abrirlas, sin sentir la curiosidad de averiguar lo que ocurría al otro lado de cada una de sus fronteras. Aquellas conferencias de París; aunque no hubieran aumentado en nada la altura científica de Couture, habrían de representar siempre el reconocimiento de su jerarquía como expositor y divulgador del moderno derecho procesal.

También hay que hablar de Couture como prologuista. Porque sus prólogos nunca fueron formularios ni se redujeron a meras presenta. ciones; fueron estudios exhaustivos de los libros que prologaba, cuando

(46).-El texto de las conferencias 7 mesa redonda acerca de la interpretación e int tegración de las leyes procesales" se publicó en la "Revista de la Escuela de Jurispruden. cia de México" núms. 43 y 44 de julio-setiembre y octubre-diciembre de 1949, habiéndose im. preso también una edición separada.

(47).-Véase mi nota en "Revista de Derecho Procesal", año VIll (1950), parte 24, págs. 97 y sigts. 
no de toda la obra del autor o de la escuela a que el libro pertenecíc. Tenía la visión clara de lo que presentaba, el acierto en la elección de los puntos salientes y de los conceptos generales. De sus prólogos, como de sus notas bibliográficas, algún lector superficial habrá podido creer en una inclinación a la alabanza 0 , al menos, a la generosidad en una ausencia de crítica. Es cierto que Couture pocas veces censuraba; al menos expresamente; pero quizás sus censuras fueron tácitas; cuando la crítica había de ser desfavorable, prefería eludirla. Lo mismo ocurría en sus prólogos: él no hubiera hecho nunca la presentación de lo impresentable.

Tomo el primero, uno que yo le pedí on 1945: el dedicado a "Providencias cautelares", de Calamandrei (48). Lo releo ahora, once años después de haber sido escrito y siento aumentado el asombro de la primera leciura; porque los cñ̃os que han pasado son la viva justificación de todo lo que entonces dijo Couture: ¡Cuanta nobleza y cuanta humildad hay en ese estudio! No se limita al libro que prologa ni a su autor; se extiende a la escuela italiana de derecho procesal; y no se detiene aún en ella; contempla toda la escuela jurídica. Está escrito en 1945; Italia se encuentra vencida; pero el espíritu justiciero de Couture se alza para decir "Ahor $\ddot{a}$ que han acontecido tantas cosas, en un momento en que Italia, vencida por tantos fenómenos de orden político, militar $y$ económico, busca en sus células nobles, en aquellas que pudieron sobrevivir a la lucha, los elementos que habrán de incrcarle su derrotero futuro, parece llegado el momento de señalar lo que el derecho debe a este país. No sólo por espiritu de justicia sino también como un modo de impedir que cundan ciertas confusiones que parecen insinuarse como triste recuerdo del destino que toca al árbol caído, es menester examinar este fenómeno en términos rigurosos. El libro que el lector tiene en sus manos vendría a stervir así más que de texto, de pretexto para meditar sobre el destino de una escuela". ¡Cuánta nobleza!. ..... al volver la mirada hacia nuestra casa: "De escuela puede hablarse, solamente, cuando en torno a una Universidad o a un Instituto se forma un conjunto tal de estudiosos que dan a su labor el mismo sentido de cooperación que en otros órdenes de la vida asegura el triunfo de los mejor organizados. Para esto es menester reunir muchas cosas. Se necesitan, ante todo, maestros. No basta una, dos o tres figuras estelares; sólo decenas de maestros auténticos hacen una escuela. Se re: quiere, asimismo, una tradición. América no tendrá escuelas hasta tanto nuestros humildes esfuerzos de hoy sean considerados, en el siglo XXI, como el balbuceo de los precursores". "Cuánta humildad!

Couture no conoce entonces a Calamandrei; habrán de pasar varios años hasta su visita a Italia en la que el maestro toscano "pondrá Florencia a sus pies"; y traza el más exacto retrato del hombre al que también acabomos de perder.

Si hubiéramos de formar una antología de Couture, este prólogo. que es la más fiel pintura de la escuela jurídica italiana, no podría faltor.

(48).- "Introducción al estudio sistemático de las providencias cautelores, traducción de Scratiago Sentis Melendo, Ed. Bibliogrática Argentina, Br. Aires, 1945. 
Otro día fué la presentación de la "Colección: Ciencia del Proceso". que él había de dirigir con Alsina y Vélez Mariconde y que se iniciaba. con los "saggi" de Chiovenda (49); nada hubiera podido decirse, con mayor precisión, para jüstificar el que fuera la obra monográfica del fundator de la escuela procesal italiana, la que abriese el camino que quienes iniciaban la Colección ansiaban recorrer.

Y cuando prologa "La certeza del Derecho", de López de Oñate (50) (ese libro del cual Sebastián Soler ha dicho que es uno de los más admirables de los últimos tiempos), y sólo se le solicitaba la justificación de que un libro no específicamente procesal figurase en una colección dedicada a la Ciencia del proceso, Couture señala no sólo su trascendencia jurídica sino también el impacto político que representa, no solo su valor en el campo del proceso sino también dentro de la teoría general del derecho.

En ctro momento ha debido presentar a nuestros lectores una producción norteamericana: "Los principios formativos del procedimiento civil", de Robert Wyness Millar (51). En medio del estudio admirable destacando la originalidad de la labor, bastará señalar la fuerza con que aprecia su nota característica: "Y como sucede tantas veces, ocurrió que en Europa fue éste un libro americano $y$ en Ámérica, un libro europeo. Colocado en el filo de dos culturas, a pesar de sus excepcionales méritos, estas páginas quedaron reservadas a lectores de selección $y$ sólo en contadas oportunidades, mós en vía indirecta que directa, llegaron a ese gran público para cuya cultura, en último término, se escriben los libros".

Al lado de estos prólogos a libros cuyos autores Couture no conocía, la situación contraria se da cuando presenta "Los Problemas generales del derecho", de James Goldschmidt (52). El autor en su peregrinaje por el mundo ha buscado refugio y serenidad de espíritu en Montevideo. Y allí las lecciones contenidas en el volumen se fueron preparando hasta el momento de la muerte fulminante. La compenetración con el autor, la apreciación de la "aventura jurídica" de ese autor; la percepción exacta del carácter de páginas de premuerte, dan a este prólogo un especial significado.

Entre tantas presentaciones de obras traducidas, no podemos dejar de hacer referencia a la dedicada a una obra argentina: las "Anotaciones al Código de procedimientos en lo civil y comercial de la provincia de Santa Fe", de Cabal y Átienza (53); es uno de los prólogos más antiguos de Couture; pero su estilo, o mejor su sistema, no es distinto del que se

(49).- "Ensayos de Derecho Procesal Civil" trad. de Santiago Sentis Melendo, "Ejea" Bs. Aires, 1949, 3 volúmenes.

(50). -Flavio López de Oñate, "La certeza del derecho", trad. de Santiago Sentis Molendo y Marino Ayerra Redín, 'Ejea", Bs, Aires, 1953.

(51).--Robert Wynes Millar, "Los principios formativos del procedimiento civil", trad.. del inglés $y$ notas por la doctora Catalina Brossmann. Ed., Ediar (S.A.) Bs. Aires, 1945.

(52).-James Goldschmidt, "Problemas generales del derecho" (obra pósiuma), Ed. Depalma, Bz. Aires, 1944.

(53).-Justo 1. Cabal y Antonio Atienza. "Anotaciones al Código de Proced. Civil y Ca. mercial de la Prov. de Santa Fe". Libr. ₹ Ed. Clencia, Rosario 1940. 
encuentra en los que dedicó a las otras obras a que me he referido: se aprecia la obra; se observan sus propósitos y se perciben sus resultados. Contempla aquí no sólo las "Anotaciones" sino también el cuerpo legal; porque "código y notas funcionarán en el futuro como una sola unidad jurídica": porque los espíritus prócticos "se servirán para su trabajo del texto de este libro, en lugar de examinar las disposiciones legales en la bdición oficial del código". Y así ha sido.

Un último prólogo que todavía no ha visto la luz es el que Couture puso al "Elogio de los jueces escrito por un obogado", de Calamandrei. De esa obra a la que refiriéndose a su primera edición, llamó Couture "una joya de gracia literaria", le correspondió después prologar la traducción de la tercera; es el último prólogo, al menos que yo conozca, que Couture escribió. La tragedia se ha ensañado con esta publicación que aparece cuando autor $\mathrm{y}$ prologuista han desaparecido (54). Entre el próloyo a "Providencias coutelares" y el prólogo del "Elogio" se ha producido el conocimiento personal entre Calamandrei y Couture; se han encontrado en Florencia; es Calamandrei quien ha mostrado a Couture aquel "milagro de la civilización". Pero en este encuentro entre las dos personalidades se ha producido otro milagro: el conocimiento anterior al encuentro era ya perfecto.

Si como profesor llegaba a ocupar el Decanato de la Facultad, como abogado se le designaba para ocupar el del Colegio; y siendo Decano Couture se organizó la VII Conferencia Interamericana de Abogados, de la cual el Presidente del Comité Ejecutivo de la Inter American Bar Association pudo decir: "En mi experiencia de todas las conferencias, no he visto nunca, y no espero ver, otra mejor planeada, mejor conducida $y$ con mejores resultados que ésta".

Con toda la importancia que su actuación en el Decanato ofreció, Couture nos deja, en cuanto a la función del abogado, una creación de valor permanente: "Los mandamientos del abogado". Son diez máximas en las que se concreta la actitud del abogado ante el Derecho y ante li Justicia: frente al cliente, al adversario y al juez. En ese pequeño volumen. de pocas docenas de páginas, hay, además de la formulación de los mandamientos, la exégesis de los mismos.

Los "Mandamientos", de Couture, son hoy en día libro de texto de los abogados de muchos países. No ha faltado en la Argentina -y es satisfacción proclamarlo-, colegio de abogados que, en el acto de prestar juramento los que $\alpha$ él se incorporan, les haga entrega del decólogo de Couture como síntesis de lo que el abogado debe tener presente al ejercer su ministerio.

Hemos seguido la labor de Couture a lo largo de 25 años. Si no la hemos analizado, al menos la hemos repasado. Hemos aludido a su o bra no escrita $y$ hemos contemplado, en visión panorámica, la escrita, in-

(54).-Este libro aparecerá muy en breve en edición de "Fjea" que reproduce incluso en su presentación tipográfica, la 3\% edición italiana. 
cluso la que podría clasificarse como no jurídica: la obra general y la monográfica; la de codificador; la de conferenciante y la de prologuista; hemos visto a Couture situado ante el problema del ejercicio de la abogacía.

Causa asombro no cólo su calidad sino también lo ingente de su volumen, para una vida que se apagó tan pronto, y que hoy la percibimos envuelta, con frecuencia, en una atmósfera de premuerte: "Hay una ciencia, un arte, un pensamiento que adquiere un acento muy particular cuando se tiene la vida un poco llena de muerte". Pero esta idea que la encontrábamos en 1944, en el prólogo de Couture a los "Problemas generales del derecho", de Goldschmidt, nos salía de nuevo al paso en 1953 en esa maravilla que es "La Comarca y el Mundo", cuando ante "La universalidad vegetal de Río Piedras", Couture soñaba en dar a la enseñanza cierta mezcla de vida y de muerte, como uno de los mejores pasos en el raro arte de impartir el saber. Y veía -no importa que ello estuviese lejos de los conceptos jurídicos- arte de premuerte en el toreo de Manolete. Y habíamos de volver a percibir la idea en su última lección en tierra argentina, al agradecer, en Paraná, las palabras de presentación del doctor Martínez Segovia: "A estas alturas de mi vida- decía Couture repitiendo un diólogo de Paul Geraldy- ya no seré marino, ya no seré poeta, ya no seré sabio; es demasiado tarde para empezar de nuevo". "Es la idea de la muerte que se va fijando y va convirtiendo en "páginas de premuerië" muchas de las suyas, aunque no llegásemos a percibirlo, hasta que ha sido demasiado tarde, ni siquiera los que estábamos más cerca de él.

Toda esa labor examinada es de creación y de divulgación del derecho, en particular del procesal; debiendo entenderse que no solamente se crea cuando se elabora conceptos totalmente nuevos y originales sino también cuando se reelabora conceptos ya creados por otros estudiosos y hasta cuando se metodiza lo que otros elaboraron o reelaboraron; no hay labor creadora en la mera repetición, nunca posible en Couture; pero sí puede haberla en la exposición histórica de las instituciones y en la contemplación de ellas bajo prismas distintos de los utilizados anteriormente.

Couture realizó obra creadora bajo todos los aspectos. En su continua búsqueda de la exactltud de conceptos básicos deì proceso civil, en su permanente insatisfacción de los resultados obtenidos, él llegó a elaborar una doctrina de la acción, como manifestación típica del derecho de petición. Esa concepción contribuye a explicar los fenómenos procesales en forma no lograda anteriormente y quedará incorporada a la doctrina procesal como adquisición importante. Ella sólo bastaría para dar sentido científico a la obra de Couture. Pero, además, ese concepto de accićn ha servido para explicar la naturaleza procesal del concepto de jurisdicción, . y para que el panorama completo del proceso civil se pueda contemplar sin dificultad. La labor creadora de Couture no es la obra instantónea y fulminante, sino el producto del trabajo lento, metódico, continuado, en busca de una meta que nunca él consideraba alcanzada. Quizá; en sus palabras finales de la sesión de mesa redonda de la Universidad de París 
pueda encontrarse la explicación de ese contínuo luchar con la difícil evolución de los conceptos.

Pero simultaneamente con esa labor creadora y con la de no menor trascendencia de sistematización, está su tarea de divulgador del moderno derecho procesal. Una divulgación con facetas múltiples: porque es la divulgación de las concepciones ajenas, pero también de las propias; y la divulgación de sus permanentes reelaboraciones. Y es, además, la divulgación en Ámérica de la ciencia europea, y también la manifestación de que existe una ciencia procesal americana; es, sobre todo, la presencia en. Europa de esta ciencia americana.

Esto es io que, entre otras muchas cosas, Couture nos deja; es su legado a la ciencia en permanente evolución; que seguirá avanzando también ahora que él nos falta, pero permitiéndonos ver, en ocasiones, que algún paso dado con firmeza se apoyó en terreno que Couture nos dejó proparado.

Hubiera querido realizar de la obra de Couture un examen $\alpha$ fonđo; pero si mis posibilidades no llegan a más, tengo la esperanza de que no sea del todo inútil este repaso superficiali e incluso de que pueda servir de programa para la tarea, más provechosa de otros. Es tarea que debe realizarse. Puede considerarse que comienza en estos días con las "Jornadas rioplatenses", en memoria de dos grandes maestros y que debe seguirse en todo momento con arreglo a la interpretación del poeta, que había de ser grata al espíritu de Couture: "Haced un duelo de labores Y esperanzas". 